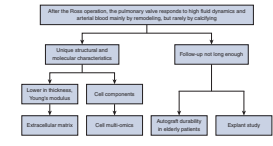

\section{ROSS PROCEDURE: WHAT CAN WE LEARN FROM THE NONSTENOTIC PULMONARY AUTOGRAFTS?}

\section{To the Editor:}

We read with great interest the recent study from Dr David and colleagues on late outcomes after the Ross procedure. ${ }^{1}$ We were intrigued by the data that after a median of 18 years, the only mode of pulmonary autograft failure was regurgitation, without even 1 case of stenosis. Consistent with the current study, data from the German Ross Registry suggested that in adult patients (mean age, 45 years) who received the Ross operation, very few cases of autograft stenosis were reported after 10 to 20 years. $^{2}$ Studies on the explanted pulmonary autografts also showed adaptive remodeling and thickening of the pulmonary valves, but these changes were not associated with incremental transvalvular gradients or calcification over time. ${ }^{3}$

Why don't pulmonary autografts calcify in the aortic position? There are more questions than answers. Structural valve deterioration is much more common after implantation of pericardial and tissue-engineered prostheses than pulmonary autografts, and leaflet calcification is a major cause of bioprosthetic failure. Moreover, normally developed

\footnotetext{
The Editor welcomes submissions for possible publication in the Letters to the Editor section that consist of commentary on an article published in the Journal or other relevant issues. Authors should: • Include no more than 500 words of text, three authors, and five references. $\bullet$ Type with double-spacing. $\bullet$ See http://jtcs.ctsnetjournals.org/ misc/ifora.shtml for detailed submission instructions. • Submit the letter electronically via jtcvs.editorialmanager.com. Letters commenting on an article published in the JTCVS will be considered if they are received within 6 weeks of the time the article was published. Authors of the article being commented on will be given an opportunity of offer a timely response ( 2 weeks) to the letter. Authors of letters will be notified that the letter has been received. Unpublished letters cannot be returned.
}

pulmonary valves rarely calcify in their own position. After the Ross operation, the pulmonary autograft becomes exposed to supraphysiological hemodynamics (from pulmonary artery pressure to aortic pressure), which is associated with higher levels of $\alpha$-smooth muscle actin expressed by valve interstitial cells, transformation from quiescent to activated phenotypes, endothelial-to-mesenchymal transition, and finally, calcific nodule formation. ${ }^{4}$ Recently, high mechanical loads were reported to create microfissures on the endothelium, thereby inducing iron deposition and calcification. ${ }^{5}$ Despite these risks, the long-term freedom from calcification and stenosis might suggest favorable viability and functional integrity of the pulmonary autografts that enable appropriate adaptive remodeling and preclude the leaflets from sliding into a pathological state. However, the knowledge gap between physiological remodeling and pathological calcification remains to be crossed.

There are several possibilities to investigate the nonstenotic feature of the pulmonary valves (illustrated in Figure 1). First, heart valve biomechanics might be the key that initiates the whole pathological process. Because the biomechanical and molecular factors are intertwined, it is important to work on reliable in vivo data of heart valve dynamics. One simulation study has reported encouraging results, suggesting a direct relationship between distribution of strain on leaflets and patterns of calcification. ${ }^{6}$ Besides, lower oxygen saturation and molecular components in the venous circulation might be protective factors against calcification. In addition, the structural and molecular characteristics of pulmonary valves in comparison with aortic valves could be useful. Last, longer follow-up data of pulmonary autograft durability after the Ross operation as well as histological and molecular studies on explanted autografts might facilitate understanding of pulmonary valve remodeling and deterioration in the aortic position.

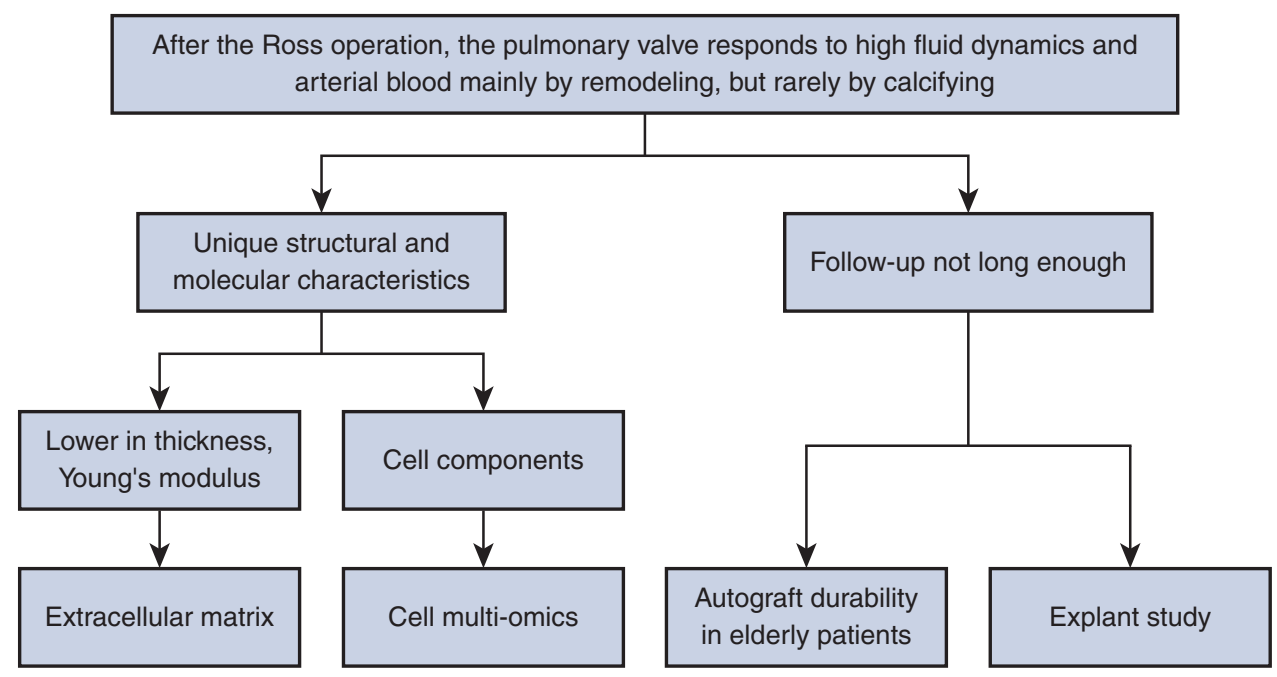

FIGURE 1. Pulmonary valves may play a role in studies on mechanisms of valve calcification. 
Authors have nothing to disclose with regard to commercial support.

In summary, although the pulmonary autografts might be subject to dilatation and insufficiency after the Ross procedure, investigations into the nonstenotic feature could help shed some light on the mechanisms of aortic valve calcification as well as design and fabrication of improved tissue prostheses.

Wenrui Ma, $M D^{a}$

Wei Zhang, $M D^{b}$

Chunsheng Wang, $M D^{a}$

${ }^{a}$ Department of Cardiac Surgery

Shanghai Institute of Cardiovascular Diseases

Zhongshan Hospital

Fudan University

Shanghai, China

${ }^{b}$ Department of Cardiovascular Surgery

Shanghai Chest Hospital

Shanghai Jiao Tong University

Shanghai, China

\section{References}

1. David TE, Ouzounian M, David CM, Lafreniere-Roula M, Manlhiot C. Late results of the Ross procedure. J Thorac Cardiovasc Surg. 2019;157:201-8.

2. Sievers HH, Stierle U, Charitos EI, Takkenberg JJ, Hörer J, Lange R, et al. A multicentre evaluation of the autograft procedure for young patients undergoing aortic valve replacement: update on the German Ross registry. Eur J Cardiothorac Surg. 2016;49:212-8.

3. El-Hamamsy I, Eryigit Z, Stevens LM, Sarang Z, George R, Clark L, et al. Longterm outcomes after autograft versus homograft aortic root replacement in adults with aortic valve disease: a randomised controlled trial. Lancet. 2010;376:524-31.

4. Mahler GJ, Frendl CM, Cao Q, Butcher JT. Effects of shear stress pattern and magnitude on mesenchymal transformation and invasion of aortic valve endothelial cells. Biotechnol Bioeng. 2014;111:2326-37.

5. Morvan M, Arangalage D, Franck G, Perez F, Cattan-Levy L, Codogno I, et al. Relationship of iron deposition to calcium deposition in human aortic valve leaflets. J Am Coll Cardiol. 2019;73:1043-54.

6. Halevi R, Hamdan A, Marom G, Lavon K, Ben-Zekry S, Raanani E, et al. A new growth model for aortic valve calcification. J Biomech Eng. 2018;140(10): https://doi.org/10.1115/1.4040338.

\section{https://doi.org/10.1016/j.jtcvs.2019.08.077}

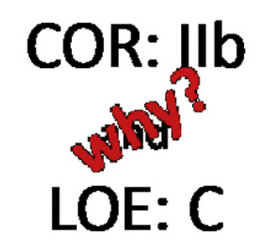

REPLY: WHY STILL IIB AND C? Reply to the Editor:

In a selected group of patients, the Ross operation offers excellent long-term outcomes. ${ }^{1}$ Especially in young patients, the Ross operation improves quality of life and increases survival when compared with mechanical valve substitutes. ${ }^{2}$ These findings are related to the advantages of the living pulmonary autograft being implanted in the aortic position.
The letter to the Editor by Ma and colleagues focused on the fact that failure of the pulmonary autograft in aortic position over time is not related to valve stenosis. The reason for this observation remains unclear. Comparing pulmonary and aortic roots using different methodologies will increase our understanding of valve pathophysiology and on the development of aortic valve disease. Histologic analyses, molecular studies, and hemodynamic investigations could be used to accomplish this. Therefore, the letter by Ma and colleagues adds an important piece of information, not only with regards to the Ross operation.

The reason why pulmonary autografts do not develop valve stenosis over time, when implanted in aortic position, remains speculative and most likely multifactorial. As the autograft adopts to the systemic pressure over time, it may be that the length of follow-up may still be too short to observe pulmonary valve stenosis. Autograft age may also play a role in that older autografts could lose their ability to adopt to systemic pressure and, therefore, be more likely to fail over time.

As the autograft is the only "living" valve substitute available for the aortic position, the protective role of viable tissue may be the most important factor. When autografts do fail, it is mainly due to valve regurgitation. Even when this happens, however, the autograft can be preserved either by valvesparing techniques or by "Ross reversal" in the majority of patients. ${ }^{3,4}$ Correct technical implantation of the tricuspid autograft should exclude valve deterioration over time due to flow alterations causing increased stress on valve cusps.

As the pulmonary autograft has been shown to have principally the same architecture compared with the aortic root, it appears to be the ideal substitute for the aortic position. ${ }^{5}$ One can therefore argue that the current guideline recommendation (2017) is too conservative: "the Ross procedure, when performed by an experienced surgeon, may be considered in young patients when vitamin $\mathrm{K}$ antagonist is contraindicated or undesirable." (Class IIb recommendation, level of evidence C). ${ }^{6}$

Given that there is increasing evidence that the Ross operation is the best procedure to treat aortic valve stenosis in young and middle-aged adults, ${ }^{1-4,7,8}$ one can argue that the guideline level of recommendation should be increased. This has been addressed by surgical experts of the Ross procedure already in 2014. ${ }^{9}$ The letter by Ma and colleagues highlights another important aspect of the advantage of the Ross procedure. It may be time to not only re-evaluate the current guidelines, but to apply this current knowledge on future research in the field of aortic valve disease.

Martin Misfeld, MD, PhD

Michael A. Borger, MD, PhD

University Department for Cardiac Surgery

Heart Center Leipzig

Leipzig, Germany 